\title{
The relationship between tumor necrosis factor- $\alpha$ polymorphisms and gastric cancer risk: An updated meta-analysis
}

\author{
WENXIAN ZHENG $^{1 *}$, SHUISHENG ZHANG $^{2 *}$, SHENFENG ZHANG ${ }^{3 *}$, LI MIN $^{4}$, YIHONG WANG $^{5}$, \\ JIAN XIE ${ }^{5}$, YONG HOU ${ }^{5}$, XIUFANG TIAN ${ }^{5}$, JIAN CHENG ${ }^{5}, \mathrm{KUN} \mathrm{LIU}^{5}$, DEGUO XU $^{5}$, XINSHUANG YU $^{5}$, \\ ZHEN LIU ${ }^{5}$, YAJUAN LV ${ }^{5}$, NING LIANG ${ }^{5}$, JIANDONG ZHANG ${ }^{5}$, FENGJUN LIU ${ }^{5}$ and YUAN TIAN ${ }^{5}$ \\ ${ }^{1}$ Department of Oncology, Shanghai Jiaotong University Affiliated Sixth People Hospital, Shanghai 200233; \\ ${ }^{2}$ Department of Abdominal Surgical Oncology, National Cancer Center/Cancer Hospital, Chinese Academy of \\ Medical Sciences and Peking Union Medical College, Beijing 100021; ${ }^{3}$ Department of Oncology, Zaozhuang \\ Municipal Hospital of Shandong Province, Zaozhuang, Shandong 277101; ${ }^{4}$ Department of Gastroenterology, \\ Beijing Medical University, National Clinical Center for Digestive Disease Center, Key Laboratory for \\ Precancerous Lesion of Digestive Disease, Beijing 100050; ${ }^{5}$ Department of Radiation Oncology, Shandong \\ Provincial Qianfoshan Hospital, Shandong University, Jinan, Shandong 250014, P.R. China
}

Received April 21, 2017; Accepted June 21, 2017

DOI: $10.3892 /$ br.2017.934

\begin{abstract}
The aim of the present study was to evaluate the relationship between tumor necrosis factor- $\alpha(T N F-\alpha)$ and the development of gastric cancer, and to investigate whether it can be used as a biological marker for gastric cancer. In the current study, a new meta-analysis was performed to assess the association between $T N F$ - $\alpha$ gene polymorphisms and gastric cancer susceptibility. Subgroup analyses based on ethnicity, control population source and non-cardia cancers were also conducted. Summary odds ratios (ORs) with $95 \%$ confidence intervals (CIs) were calculated using a random-effects model. $T N F-\alpha 308$ polymorphisms indicated a significant relationship with gastric cancer risk among a normal population [GA/AA vs. GG; 1.17 (1.10-1.23)]. In analysis stratified by ethnicity, $T N F-\alpha 238$ displayed an association with gastric cancer risk in eastern populations [GA/AA vs. GG: 1.24 (1.02-1.50)], but not in western populations [GA/AA vs. GG: $0.96(0.79-1.18)]$. The overall ORs (95\% CIs) for TNF- $\alpha$ 857, TNF- $\alpha 1031$ and TNF- $\alpha 863$ were 1.13 (1.04-1.24), 0.94 (0.85-1.05) and 0.89 (0.78-1.02), respectively, under dominant genetic model comparison. Among the above three SNPs, only TNF- $\alpha 857$ was robustly associated with gastric cancer inclination, and
\end{abstract}

Correspondence to: Dr Yuan Tian, Department of Radiation Oncology, Shandong Provincial Qianfoshan Hospital, Shandong University, 16766 Jingshi Road, Jinan, Shandong 250014, P.R. China E-mail: tytytianyuan@aliyun.com

\section{"Contributed equally}

Key words: tumor necrosis factor- $\alpha$, polymorphisms, gastric cancer, risk, meta-analysis this association remained consistently robust when limited to non-cardia gastric cancers [GA/AA vs. GG: 1.16 (1.03-1.31)]. $T N F-\alpha 308$ and $T N F-\alpha 857$ genotypes were potential risk factors of statistical significance in gastric cancer, and $T N F-\alpha 238$ indicated to be significantly associated with gastric cancer risk only in eastern populations. TNF- $\alpha 1031$ and $T N F-\alpha 863$ were not significantly associated with gastric cancer risk.

\section{Introduction}

Although the incidence and mortality of gastric cancer have both declined in most areas of the world, gastric cancer is still the fourth most frequent cancer occurred and the second leading cause of cancer related death worldwide, and is especially higher among East Asian countries (1). Thus, identification of possible risk factors is especially essential for the prevention of gastric cancer. It is suggested that gastric cancer is relevance to many factors, including gastric precursor lesions, Helicobacter pylori infection and genetic polymorphisms. Among all polymorphisms, the variants of pro- and anti-inflammatory cytokines such as interleukin (2) and tumor necrosis factors (TNFs) (3) were most extensively investigated. $T N F-\alpha$ is a cytokine initially taken as a serum factor causing necrosis of transplanted tumors and it serves an important role in host defense against infectious diseases, whereas excessive expression product may lead to organ failure and a strong inflammatory response which may modify gastric cancer risk (4).

Previously, identification of polymorphisms of $T N F$ - $\alpha$ gave some suggestions on understanding the genetic predisposition of gastric and colorectal cancers (5). The expression level of TNF- $\alpha$ was proved to be obviously affected by polymorphisms in its promoter region, and previous studies have identified that such polymorphisms at 238 (rs361525), 308 (rs1800629), 857 (rs1799724) and 1031 (rs1799964) positions may influence 
production of $T N F-\alpha$ (6-9). However, the hypotheses that $T N F-\alpha$ polymorphisms may be associated with gastric cancers are still in controversial and the results of previous association studies have been largely inconclusive.

Most of the published studies about $T N F-\alpha$ polymorphisms just refer to a small or modest sample size, and none of them were able to get a reliable conclusion. Therefore, the authors conducted a new meta-analysis to review studies that have examined those polymorphisms, to further investigate the relevance between polymorphisms of $T N F-\alpha$ and the risk of gastric cancer.

\section{Materials and methods}

Data sources. The authors searched for all articles that had been published about the relevance between $T N F-\alpha$ polymorphisms and the inclination of gastric cancer, applying the following topics in the MEDLINE, PubMed, EMBASE and the Cochrane library: ['Tumor Necrosis Factor-alpha' (MeSH) OR (Tumor Necrosis) OR TNF] AND ['Polymorphism, Genetic' (MeSH) OR polymorphism OR polymorphisms OR risk] AND (gastric cancer). All articles were updated on July 15, 2013. References of all primary studies and review articles were reviewed for additional references. The search was carried out by two individual researchers to confirm that no published papers were missed.

Criteria for inclusion and exclusion. Subjects enrolled in the study must meet the following criteria: i) Case-control studies about the relevance between $T N F$ - $\alpha$ polymorphisms and gastric cancer; ii) available genotype frequencies in cases and controls provided; and iii) self-reported results and risk assessment and/or displayed data necessary for evaluating OR with $95 \%$ CI. The authors eliminated studies that crossing with other studies or reported with data from the same authors.

The process of data extraction. The data was picked up independently by two scientists. Related information of the author's last name, publication year, country of origin, study population origin, genotypes and the number of cases and controls were recorded. The number of studies on TNF- $\alpha 308, T N F-\alpha 238$, TNF- $\alpha 857, T N F-\alpha 1031, T N F-\alpha 863$ and gastric cancer were $33,16,8,6,5$, respectively. More than half of the studies took frequency-matched controls to cases by age and sex.

Statistical data analysis. The authors used the Hardy-Weinberg equilibrium to compare the observed genotype frequencies with expected genotype frequencies in controls of all studies. ORs and $95 \%$ CIs were adopted to evaluate the robust relationship between $T N F$ - $\alpha$ polymorphisms and inclination of gastric cancer under homozygote comparison and dominant genetic model comparison. Random-effects models were taken to compute overall summary ORs and 95\% CIs. Study populations were divided into western (Europe and America) or eastern (China, Korea, India and Iran).

The importance of the overall ORs was assessed by the $\mathrm{Z}$-test, in which two-sided $\mathrm{P}<0.05$ was considered to indicate a statistically significant difference. The Q-statistic was adopted to evaluate the heterogeneity among studies, and $\mathrm{P}<0.1$ was considered as a significant gap. The $I^{2}$-statistic

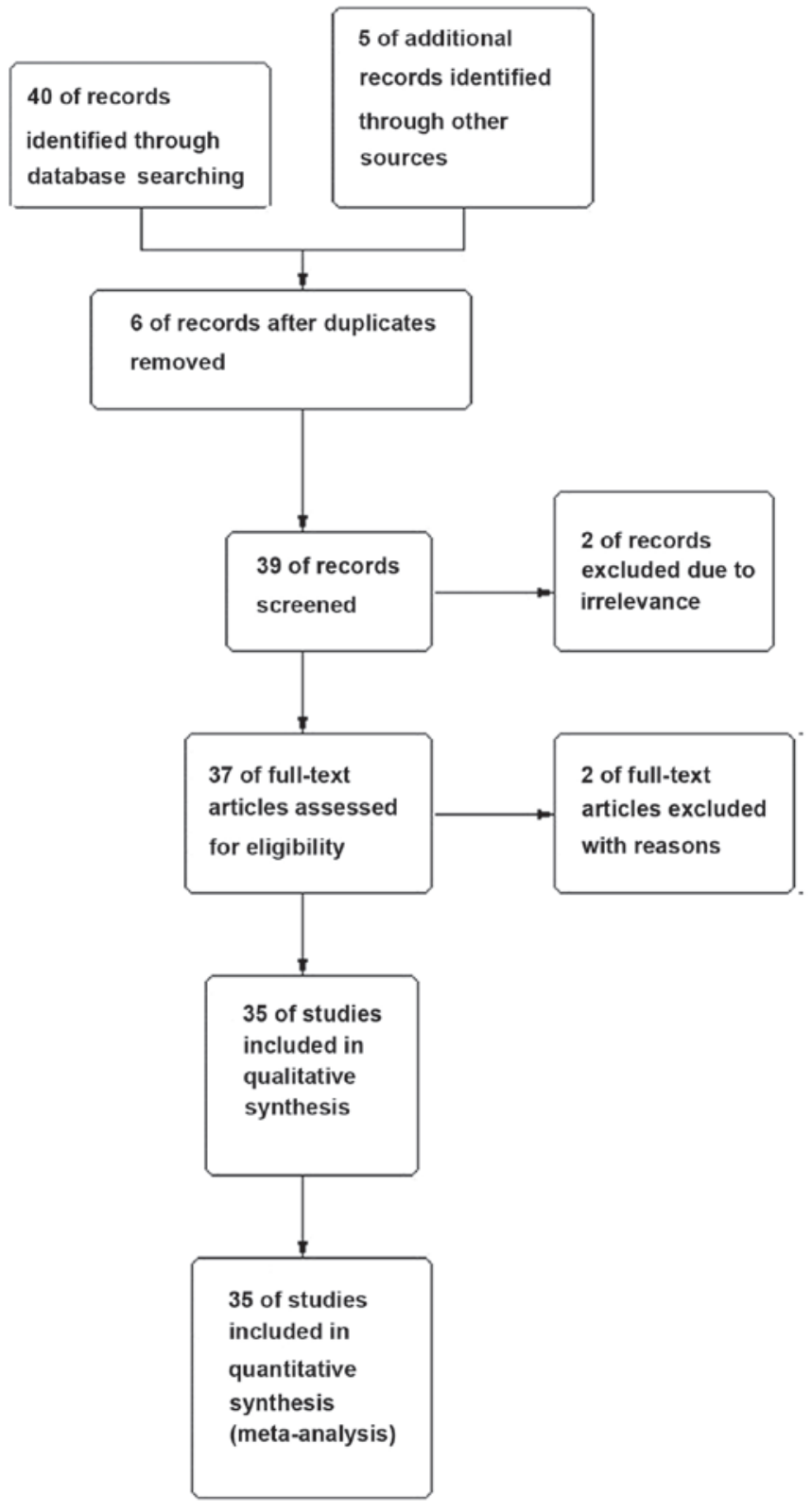

Figure 1 . The process of the study selection.

can also be taken to check test heterogeneity efficiently, with $I^{2}<25 \%, 25-75 \%$ and $>75 \%$ considered to display low, moderate and high degree of inconsistency, respectively. Begg's funnel plot was taken to gauging the underlying publication bias (10). As for the sensitivity analysis, relatively smaller studies were rejected and the overall ORs (95\% CIs) were checked again. All data analyses were carried out by STATA software (version 12.0; STATA Corporation, College Station, TX, USA).

\section{Results}

Characteristics of studies. The authors searched 355 records. Following elimination of duplicated and irrelevant records by checking the titles and abstracts, 35 full-text articles were picked up for intensive study. The process of selection process was shown in (Fig. 1). Each risk of bias item for each included study was shown in (Figs. 2 and 3). 


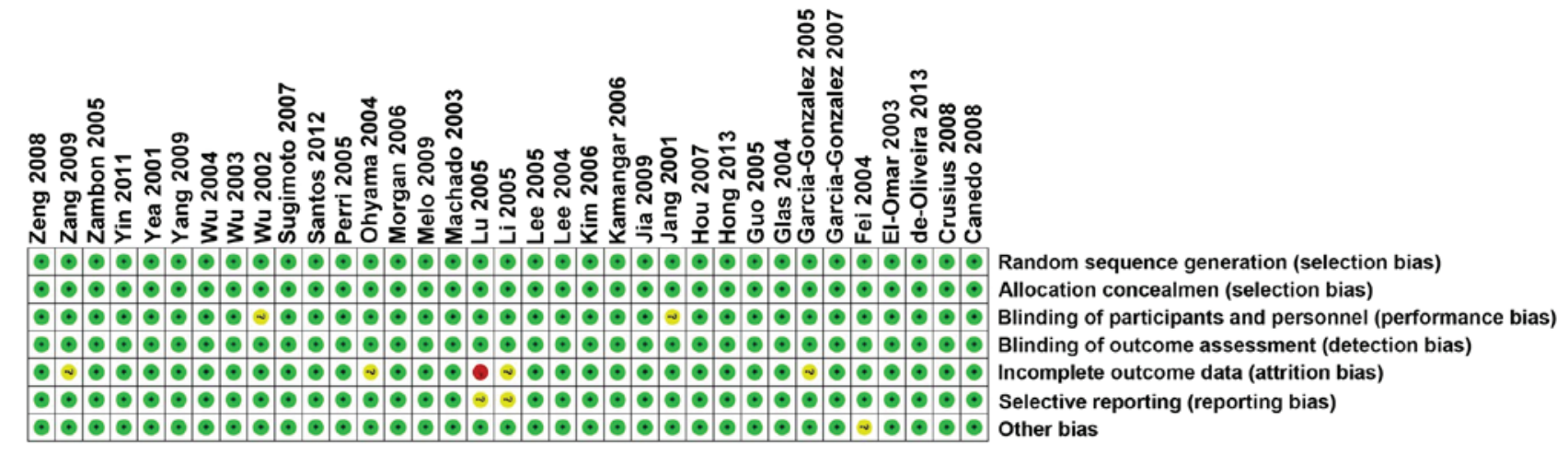

Figure 2. Risk of bias summary. Authors' judgments concerning each risk of bias item for each included study.

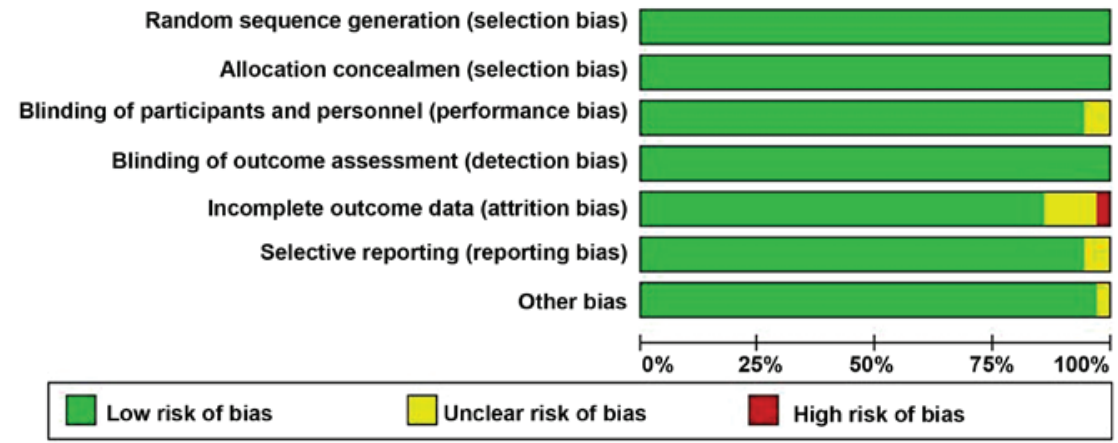

Figure 3. Risk of bias graph. Authors' judgments concerning each risk of bias item presented as percentages across all included studies.

A

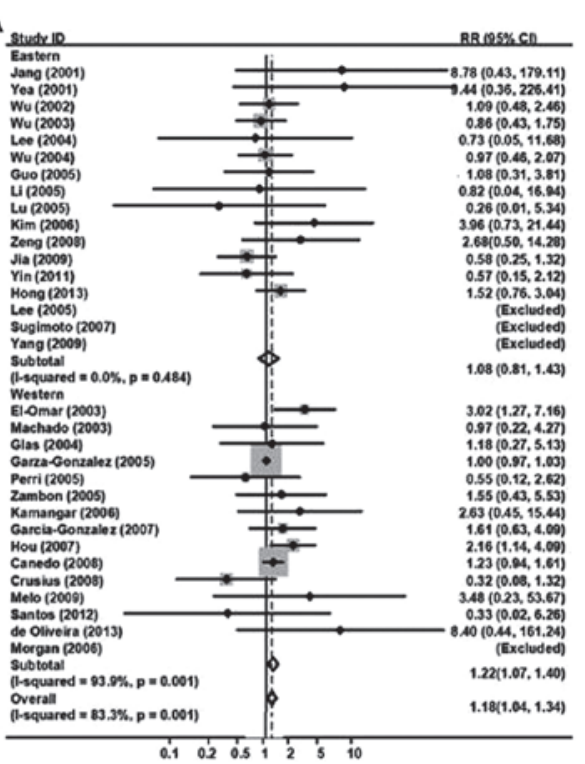

C

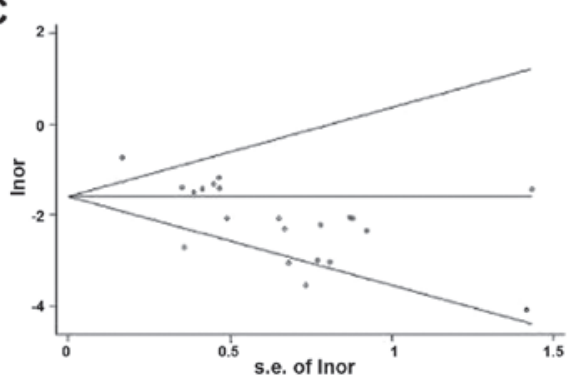

B

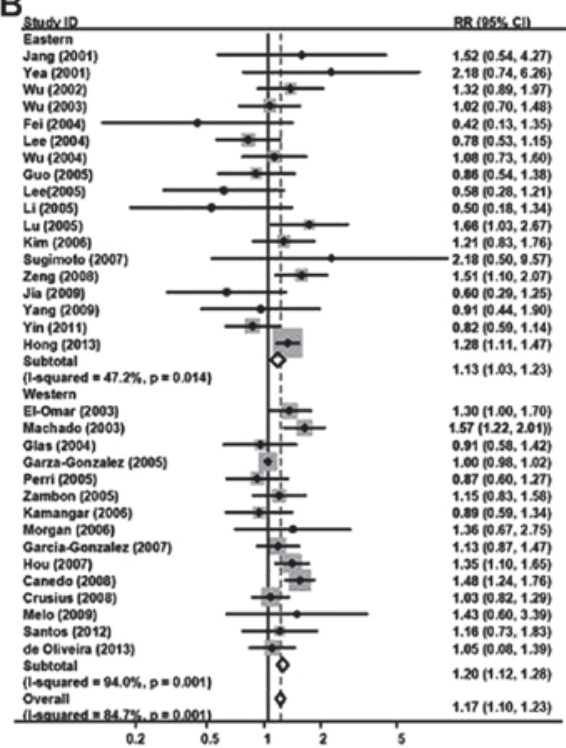

D

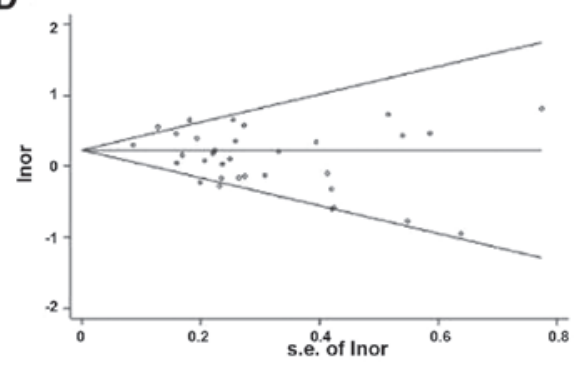

Figure 4. The association between tumor necrosis factor- $\alpha 308$ and gastric cancer. (A) AA vs. GG, Forest plot; (B) AA/GA vs. GG, Forest plot; (C) AA vs. GG, Begg's funnel plots; (D) AA/GA vs. GG, Begg's funnel plots. 


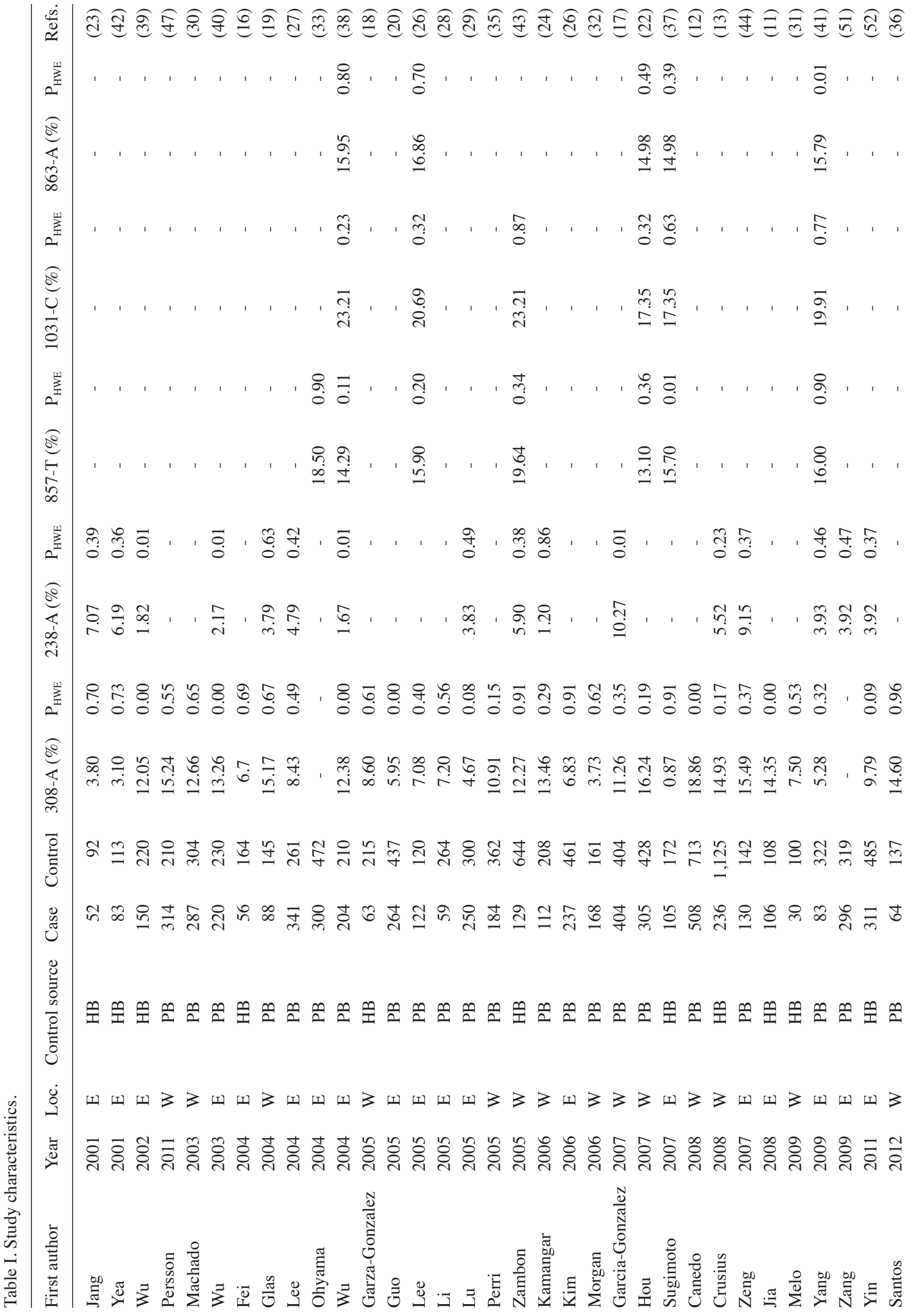


A total of 35 studies with 8,147 cases and 12,182 controls were included in this analysis (Fig. 4). The most popular investigated genotypes were $T N F-\alpha 308, T N F-\alpha 238$, which were presented in 33 and 16 studies, respectively (11-44). Other genotypes, such as TNF- $\alpha$ 857,TNF- $\alpha$ 863, and TNF- $\alpha 1031$ were also included in this meta-analysis. Genotype and allele distributions of TNF- $\alpha 308$ are presented in Table I. Median frequencies of $T N F-\alpha 308 \mathrm{~A}$ allele were $13.46 \%$ in western populations and $7.20 \%$ in eastern populations. Corresponding frequencies for the $T N F-\alpha 238 \mathrm{~A}$ allele were 5.52 and $3.92 \%$, respectively. While the frequencies for TNF- $\alpha 857, T N F-\alpha 1031$, $T N F-\alpha 863$ were $19.64,20.28,14.98 \%$, respectively in western populations and $15.90,20.30,15.87 \%$, respectively in eastern populations.

TNF- $\alpha$ 308. Fig. 4A displayed the random-effect overall OR (95\% CIs) of TNF- $\alpha 308$ polymorphisms under homozygous genotype comparison [AA vs. GG: 1.18 (1.04-1.34)]. Since the frequencies of AA were too low, AA and AG groups were summed up as 'A carriers' groups for subsequent comparison with GG groups, which did not change the previous conclusion much [GA/AA vs. GG: 1.17 (1.10-1.23); Fig. 4B].

Classified by ethnicity, it reported an obvious relevance between $T N F-\alpha 308$ and gastric cancer inclination in eastern populations [AA vs. GG: 1.08 (0.80-1.42); GA/AA vs. GG: 1.13 (1.03-1.23), random-effects model]. A similar association was also identified in western populations (AA vs. GG: 1.22 (1.07-1.40); GA/AA vs. GG: 1.20 (1.12-1.28), random-effects model).

Analysis stratified by control population source (hospital-based, HB or population-based, PB) was also conducted (Table II). There was an obvious association between TNF- $\alpha 308$ and gastric cancer inclination in both HB subgroup [GA/AA vs. GG: 1.13 (1.04-1.23)] and PB subgroup [GA/AA vs. GG: 1.19 (1.10-1.28), AA vs. GG: 1.35 (1.11-1.64)]. For non-cardia cancers only, the summary ORs (95\% CIs) for GA/AA vs. GG and AA vs. GG were 0.98 (0.86-1.12) and 1.01(0.67-1.54), respectively, which were not statistically significant (Table II). When the analysis was limited to $H$. pylori-positive cases, these ORs (95\% CIs) for AA vs. GG and GA/AA vs. GG were 2.07 (0.74-5.79) and 1.27 (1.04-1.55), respectively.

For publication bias investigation, Fig. 4C and D used Begg's funnel plot for the association between $T N F-\alpha 308$ and the cancer risk under homozygous and dominant genetic model comparison, and no evidence for bias was identified using Egger's weighted regression method (AA vs. GG, P for bias=0.43; GA/AA vs. GG, P for bias=0.20). To further confirm these reports, the authors carried out the sensitivity analysis. It indicated that there was little modification of the assessment following rejection of any single studies.

$T N F-\alpha 238$. Analyzed by the same procedure as $T N F-\alpha 308$ above, Fig. 5A and B summarized the ORs and 95\% CIs for the associations between $T N F-\alpha 238$ polymorphisms and overall risk of the gastric cancer [AA vs. GG: $1.29(0.75-2.20)$; GA/AA vs. GG: 1.10(0.98-1.26), random-effects model].

In the analyses stratified by ethnicity, the ORs (95\% CIs) of $T N F-\alpha 238$ and gastric cancer risk in eastern populations were $1.96(0.94-4.07)$ for AA vs. GG and $1.24(1.02-1.50)$ for 
Table II. Overall and group-specific summary statistics for TNF- $\alpha 308, T N F-\alpha 238, T N F-\alpha 857, T N F-\alpha 1031$ and TNF- $\alpha 863$ in gastric cancer.

Test of

Test of association

OR $(95 \% \mathrm{CI}) \quad$ P-value $(\mathrm{Z}$ test $) \quad \overline{\mathrm{I}^{2}(\%) \quad \text { P-value }}$

\section{$T N F-\alpha 308$}

Hospital based

Population based

Non-cardia cancers

H.pylori-positive

No. of studies

Comparison

AA vs. GG

$\mathrm{GA}+\mathrm{AA}$ vs. GG

AA vs. GG

$\mathrm{GA}+\mathrm{AA}$ vs. GG

AA vs. GG

$\mathrm{GA}+\mathrm{AA}$ vs. GG

AA vs. GG

$\mathrm{GA}+\mathrm{AA}$ vs. GG

$1.00(0.86-1.15)$
$1.13(1.04-1.23)$
$1.35(1.11-1.64)$
$1.19(1.10-1.28)$
$1.14(0.75-1.72)$
$0.98(0.86-1.12)$
$2.07(0.74-5.79)$
$1.27(1.04-1.55)$

AA vs. GG

Hospital based

Population based

Non-cardia cancers

$$
\mathrm{GA}+\mathrm{AA} \text { vs. GG }
$$

3.35 (1.46-7.67)

AA vs. GG

GA + AA vs. GG

AA vs. GG

$\mathrm{GA}+\mathrm{AA}$ vs. GG

$0.84(0.65-1.11)$

$0.51(0.22-1.20)$

$1.22(1.04-1.43)$

$3.04(0.90-10.20)$

$1.08(0.80-1.47)$

TNF- $\alpha 857$

$\begin{array}{ll}\text { Hospital based } & 2 \\ & 2 \\ \text { Population based } & 6 \\ & 6 \\ \text { Non-cardia cancers } & 5 \\ & 5\end{array}$

TNF- $\alpha 1031$

$\begin{array}{ll}\text { Hospital based } & 4 \\ & 4 \\ \text { Population based } & 2 \\ & 2 \\ \text { Non-cardia cancers } & 4 \\ & 4\end{array}$

TNF- $\alpha 863$

$\begin{array}{ll}\text { Hospital based } & 1 \\ & 1 \\ \text { Population based } & 4 \\ & 4 \\ \text { Non-cardia cancers } & 3 \\ & 3\end{array}$

$$
\begin{aligned}
& \text { TT vs. CC } \\
& \text { TT + TC vs. CC } \\
& \text { TT vs. CC } \\
& \text { TT + TC vs. CC } \\
& \text { TT vs. CC } \\
& \text { TT + TC vs. CC }
\end{aligned}
$$

$1.92(0.93-3.97)$

$1.08(0.88-1.33)$

$1.71(1.20-2.43)$

1.15 (1.04-1.27)

2.13 (1.46-3.09)

$1.16(1.03-1.31)$

$$
\begin{aligned}
& \text { CC vs. TT } \\
& \text { CC + CT vs. TT } \\
& \text { CC vs. TT } \\
& \text { CC + CT vs. TT } \\
& \text { CC vs. TT } \\
& \text { CC + CT vs. TT }
\end{aligned}
$$

$1.45(0.92-2.28)$

$0.85(0.75-0.97)$

$1.59(0.85-2.97)$

$1.19(0.99-1.43)$

$1.39(0.88-2.19)$

$1.00(0.88-1.14)$

AA vs. CC

$\mathrm{AC}+\mathrm{AA}$ vs. $\mathrm{CC}$

$2.62(0.60-11.38)$

AA vs. CC

$\mathrm{AC}+\mathrm{AA}$ vs. $\mathrm{CC}$

AA vs. CC

$\mathrm{AC}+\mathrm{AA}$ vs. $\mathrm{CC}$
$1.35(0.86-2.13)$

$0.81(0.70-0.95)$

$1.03(0.55-1.95)$

$0.97(0.82-1.15)$
$1.54(1.10-2.13)$

$$
\begin{gathered}
0.96 \\
0.01 \\
0.02 \\
<0.001 \\
0.53 \\
0.76 \\
0.17 \\
0.02
\end{gathered}
$$

0.01

0.12

0.12

0.02

0.07

0.61

0.08

0.46

$<0.001$

0.01

$<0.001$

0.01

0.11

0.01

0.15

0.06

0.15

0.99

0.17

0.14

0.19

0.01

0.93

0.76

$\begin{array}{rc}22 & 0.24 \\ 90 & <0.001 \\ 0 & 0.50 \\ 46 & 0.10 \\ 0 & 0.45 \\ 8 & 0.36 \\ 15 & 0.31 \\ 28 & 0.23\end{array}$

CI, confidence interval; OR, odds ratio; TNF- $\alpha$, tumor-necrosis factor- $\alpha$; H. pylori, Helicobacter pylori.

GA/AA vs. GG. Corresponding ORs (95\% CIs) were 0.69 $(0.30-1.60)$ and 0.98 (0.79-1.18) in western populations.

For GA/AA vs. GG, the overall ORs (95\% CIs) of $T N F-\alpha 238$ and gastric cancer risk was $0.84(0.65-1.11)$ in the HB subgroup and 1.22 (1.04-1.43) in the PB subgroup. For AA vs. GG, the HB subgroup demonstrated a more significant association, with a OR (95\% CI) of 3.35 (1.46-7.67). For non-cardia cancers, the OR (95\% CI) for GA/AA vs. GG genotypes was
1.08 (0.80-1.47). However, AA vs. GG genotypes were rejected for the null values to AA genotype frequency.

To rule out any possible publication bias, Begg's funnel plot were indicated in Fig. 5C and D, and no evidence for bias was detected (AA vs. GG, P for bias=0.93; AA vs. GG, p for bias $=0.31$ ). In the subgroup analyses of populations, the results did not alter obviously when the authors rejected the relatively small studies. 


\section{A}

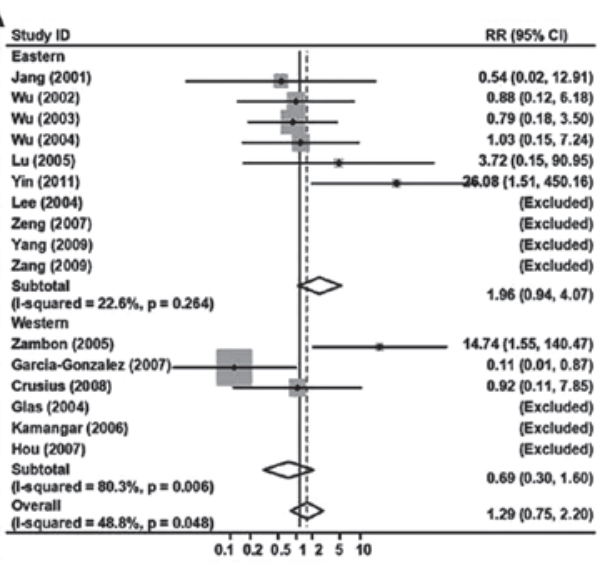

C

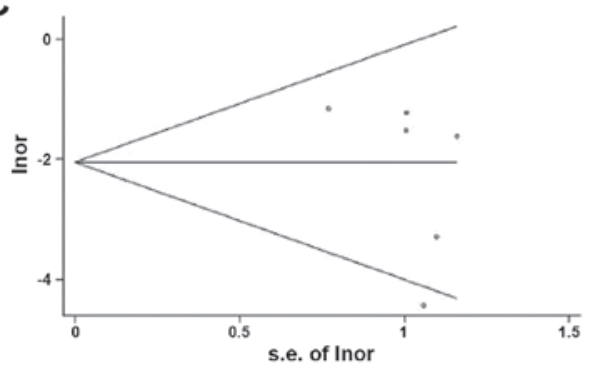

B

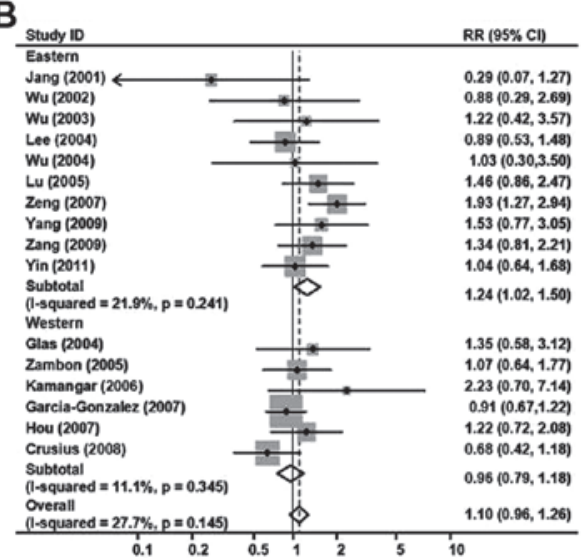

D

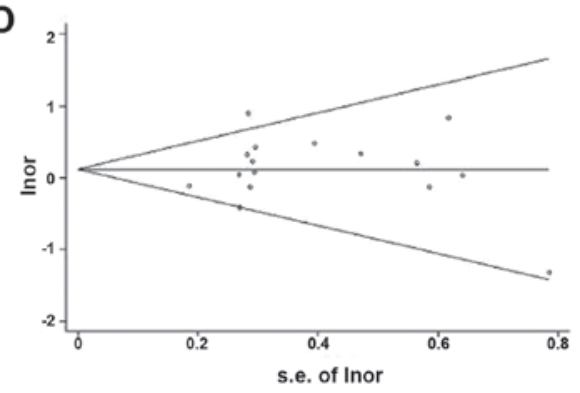

Figure 5. The association between tumor necrosis factor- $\alpha 238$ and gastric cancer. (A) AA vs. GG, Forest plot; (B) AA/GA vs. GG, Forest plot; (C) AA vs. GG, Begg's funnel plots; (D) AA/GA vs. GG, Begg's funnel plots.
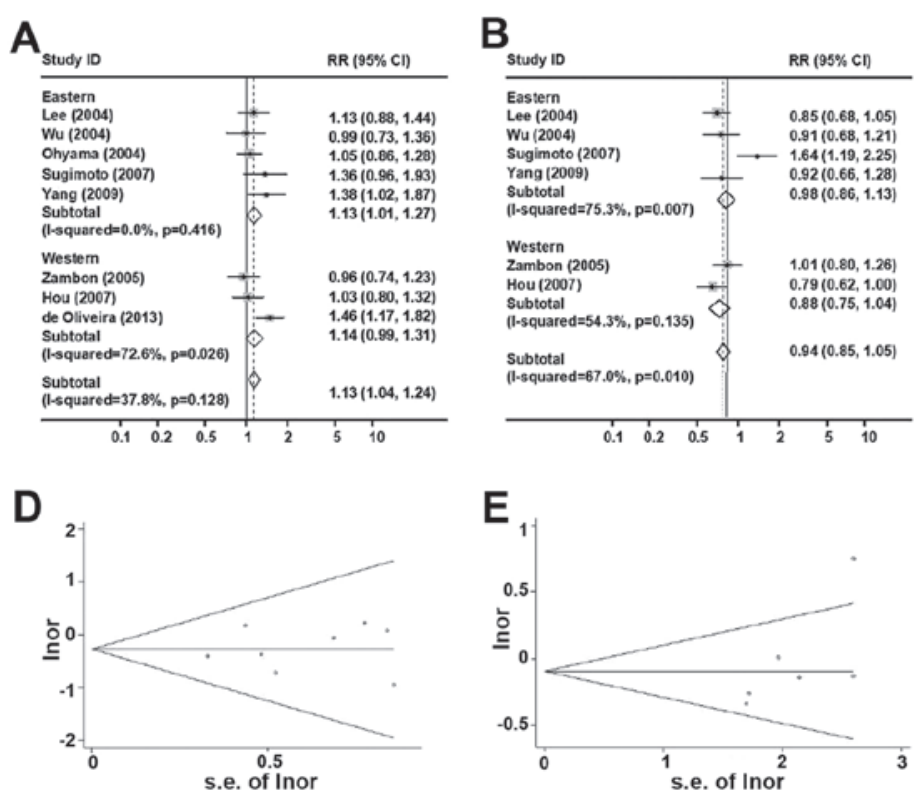
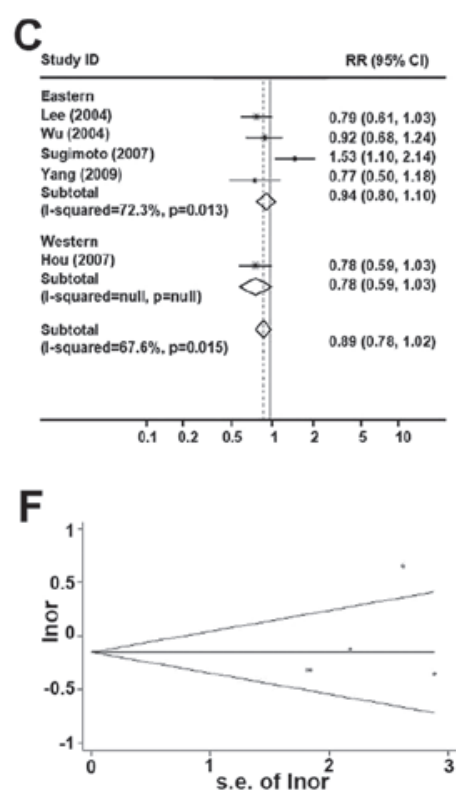

Figure 6. The association between (A and D) tumor necrosis factor- $\alpha$ 857, (B and E) 1031, (C and F) 863 and gastric cancer under dominant genetic model comparison. (A-C), Forest plot; (D-F), Begg's funnel plots.

$T N F-\alpha 857, T N F-\alpha 1031$ and $T N F-\alpha 863$. Fig. 6 summarized the ORs and $95 \%$ CIs for the relationships between the genotypes of TNF- $\alpha 857$ (TC/TT vs. CC; Fig. 3A), TNF- $\alpha 1031$ (CT/CC vs. TT; Fig. 6B), TNF- $\alpha 863$ (AC/AA vs. CC; Fig. 6C) and gastric cancer risk. Since the case populations of the included studies were small, especially the homozygous subgroups, only dominant genetic model of these three TNF- $\alpha$ polymorphisms was investigated. For overall analysis, the random-effect OR
(95\% CI) for TNF- $\alpha 857$ was 1.13 (1.04-1.24), indicating $T N F-\alpha 857$ is a potential risk factor of gastric cancer. Similar ORs (95\% CIs) were obtained in the analyses stratified by ethnicity and control population source, and also subgroup of non-cardia cancers (Table II).

TNF- $\alpha 1031$ [CT/CC vs. TT: $0.94(0.85-1.05)]$ and $T N F-\alpha 863$ [AC/AA vs. CC: 0.89 (0.78-1.02)] both seemed to be associated with a reduced risk of gastric cancer, but 
neither of them was statistically significant probably due to a small population size. Analyses stratified by ethnicity and control population source were also performed; no inconsistence between different populations was identified in Fig. 6 . However, in a population-based subgroup, the OR $(95 \% \mathrm{CI})$ was $0.81(0.70-0.95)$ for the association between $T N F-\alpha 863$ (AC/AA vs. CC) and gastric cancer risk. (Table II; $\mathrm{P}=0.007$ ).

Begg's funnel plot for the relationship among these three $T N F-\alpha$ polymorphisms and gastric cancer was presented in Figs. 6D-F. For TNF- $\alpha$ 857, TNF- $\alpha$ 1031, TNF- $\alpha$ 863, there were no evidence for bias using the method of Begg ( $\mathrm{P}$ for bias $=0.80,0.11,0.42$, respectively).

\section{Discussion}

Inflammation is usually considered as a significant factor involving in the pathogenesis of cancer, and the polymorphisms of inflammation related genes have been extensively studied for many years (2). $T N F$ - $\alpha$ is the most well-studied inflammatory factor gene in gastric cancers, and it was proved that $T N F-\alpha$ related cell functions were greatly affected by the polymorphisms in the promoter region of $T N F-\alpha$ gene (3). So far, polymorphisms at 238 (rs361525), 308 (rs1800629), 857 (rs1799724), and 1031 (rs1799964) positions were all reported to be related with risk of cancer $(3,45)$, but all the conclusions are still in controversial and the results of previous relevant studies were ambiguous. Up to now, at least five meta-analyses about the relationships between $T N F-\alpha$ polymorphisms and gastric cancer risks have been published, and even those meta-analyses held inconsistent opinions $(3,46-48)$. Furthermore, to the best of the authors' knowledge, no systematic review about all the above five SNPs has been published yet. Thus, this review and a bran-new meta-analysis can display a further proof about the relationship between those polymorphisms and the risk of gastric cancer comprehensively and systematically.

For TNF- $\alpha 308$, a total of 33 studies, more than those included in previous meta-analysis $(3,49)$, were included in the present study. Analysis on $T N F-\alpha 308$ reported a significant relationship between certain genotypes and gastric cancer risk in worldwide populations. A previous meta-analysis summarizing data on $T N F-\alpha-308$ variants have suggested some race-specific associations, with increased gastric cancer risk in different ethnic populations (3). The presented results indicated that the median prevalence of $T N F-\alpha 308 \mathrm{~A}$ allele in western populations was almost twice as high as in eastern populations (13.46 vs. $7.20 \%$ ) and the OR was also slightly higher in western populations. The PB subgroup demonstrated a much more significant association probably perhaps $\mathrm{HB}$ controls may not be representative of the universal population and such studies usually had biases. Together, the results proved that $T N F-\alpha 308$ 'A carrier' genotypes were potential risk factors of statistical significance in gastric cancers.

For $T N F-\alpha 238$, a total of 18 studies was identified to be associated with gastric cancer risks, nearly doubled those of the previous meta-analyses $(23,41,45)$. Consistent with the previous results, $T N F-\alpha 238$ polymorphisms were not significantly associated with the risk of gastric cancer when pulled all the ORs together. As a relatively large population size was used in current data, stratified analyses could be carried out. Interestingly, $T N F-\alpha 238$ presented a totally variable effect in different populations, therefore displaying an obvious relationship with gastric cancer risks in eastern populations, but not western populations. This difference could be explained by the high incidence of $H$. pylori infection among the Asian populations, so that the inflammation related genes such as TNF- $\alpha$ may serve a much more important role there. Furthermore, a significant association between $T N F-\alpha 238$ polymorphisms and gastric cancer risks was just observed in the PB subgroup but not in the HB subgroup, probably because HB controls may not be representative of the general. In addition, the incidence of $H$. pylori infection of the PB and HB subgroups may also be distinctive, which may potentially contribute to the conclusion above. In conclusion, a more detailed investigation with larger numbers of universal participants is required to confirm the relevance between the $T N F-\alpha 238$ polymorphisms and gastric cancer risks, and confirm the difference between subgroups.

The present study also stated clearly that the $\mathrm{T}$ allele of the $T N F$ - $\alpha 857$ polymorphisms be associated with a higher risk of gastric cancer. The random-effect OR (95\% CI) for $T N F$ - $\alpha 857$ was 1.13 (1.04-1.24) for overall analysis, implying $T N F$ - $\alpha 857 \mathrm{~T}$ allele is a potential risk factor of gastric cancers. The relevance was also endorsed by a report about increased transcriptional activity of the $T N F-\alpha$ gene with the $857 \mathrm{~T}$ allele and the pathological role of excessive expressed TNF- $\alpha$ (9). Additionally, it is the first time that the relationship between $T N F$ - $\alpha 857$ polymorphisms and gastric cancer risks was reviewed by a meta-analysis.

In the present meta-analysis, not enough evidence was promulgated to authenticate the existing association between $T N F-\alpha 1031, T N F-\alpha 863$ polymorphisms and gastric cancer risks. However, both of the SNPs were suggested to be related with a reduced risk of gastric cancer, according to the ORs and 95\% CIs. The association between TNF- $\alpha$ 1031, TNF- $\alpha 863$ and gastric cancers was of approximate significance, so more studies are required. Additionally, it is to be remarked that in population-based subgroup, the OR (95\% CI) for TNF- $\alpha 863$ becomes statistically significant, which supports the above suggestions from another side.

$H$. pylori infection is a key risk factor of gastric cancer. H. pylori strains and host genotypes possibly affected the host inflammatory response and epithelial-cell physiology, thus aggravated the risk of gastric cancer (50). Zambon et al (43) reported that $H$. pylori infection was associated with the $T N F-\alpha 308$ genotype. The current study demonstrated that the $T N F-\alpha 308$ polymorphisms had much more effect on the risk of catching gastric cancer in the populations with $H$. pylori infection, which indicated the existence of interaction between $H$. pylori infection and $T N F-\alpha$ pathway in gastric carcinogenesis. However, for $T N F-\alpha 238$ and other SNPs, studies with detailed $H$. pylori infection status information were so limited that data could not be stratified according to $H$. pylori infection status.

Some limitations of this meta-analysis should also be taken into account. Firstly, the sample size was too small to conduct stratified analyses, which weakened the conclusions, especially in the analyses of TNF- $\alpha 857, T N F-\alpha 1031$ and TNF- $\alpha 863$. More studies need to be picked up to achieve a much more credible conclusion. Secondly, detailed information was lacking in this meta-analysis, for which many analyses, for example analyses stratified by histology and sex, could not be carried 
out. Also, gene-gene, gene-phenotype and gene-environment interactions should also be checked in further studies provided that individual raw data were available.

Based on these analyses collectively, this systematic review had collected all the available data related with the TNF- $\alpha$ polymorphisms and gastric cancer, and this meta-analysis indicated that TNF- $\alpha 308, T N F-\alpha 238$ and $T N F-\alpha 857$ were moderately associated with an increased risk of gastric cancer. However, the association between TNF- $\alpha 1031, T N F-\alpha 863$ polymorphisms and gastric cancer risk was of similar significance. To understand the molecular carcinogenesis panorama of gastric cancer, further prospective studies in combination with analysis of other cytokines and environmental factors are required.

\section{Acknowledgements}

The present meta-analysis was supported by the Natural Science Foundation of Shandong Province (grant no. ZR2015HL078) which was been in charged by Yuan Tian. The authors would like to thank all members of the Oncology Lab of Qianfoshan Hospital. We would like to thank Peking University and Shandong University for assistance with some statistical analyses.

\section{References}

1. Parkin DM, Bray F, Ferlay J and Pisani P: Global cancer statistics, 2002. CA Cancer J Clin 55: 74-108, 2005.

2. Camargo MC, Mera R, Correa P, Peek RM Jr, Fontham ET, Goodman KJ, Piazuelo MB, Sicinschi L, Zabaleta J and Schneider BG: Interleukin-1beta and interleukin-1 receptor antagonist gene polymorphisms and gastric cancer: A meta-analysis. Cancer Epidemiol Biomarkers Prev 15: 1674-1687, 2006.

3. GorouhiF,IslamiF, BahramiH and KamangarF: Tumour-necrosis factor-A polymorphisms and gastric cancer risk: a meta-analysis. Br J Cancer 98: 1443-1451, 2008.

4. Strieter RM and Kunkel SL: The immunopathology of chemotactic cytokines. Adv Exp Med Biol 351: 19-28, 1993.

5. Campbell DA, Field M, McArdle CS, Cooke TG and Gallagher G: Polymorphism at the tumour necrosis factor locus: A marker of genetic predisposition to colorectal cancer? Lancet 347: 1706, 1996.

6. Huizinga TW, Westendorp RG, Bollen EL, Keijsers V, Brinkman BM, Langermans JA, Breedveld FC, Verweij CL, van de Gaer L, Dams L, et al: TNF-alpha promoter polymorphisms, production and susceptibility to multiple sclerosis in different groups of patients. J Neuroimmunol 72: 149-153, 1997.

7. Hellmig S, Fischbach W, Goebeler-Kolve ME, Fölsch UR, Hampe J and Schreiber S: A functional promotor polymorphism of TNF- $\alpha$ is associated with primary gastric B-Cell lymphoma. Am J Gastroenterol 100: 2644-2649, 2005.

8. Lindholm E, Bakhtadze E, Cilio C, Agardh E, Groop L and Agardh CD: Association between LTA, TNF and AGER polymorphisms and late diabetic complications. PLoS One 3: e2546, 2008.

9. Higuchi T, Seki N, Kamizono S, Yamada A, Kimura A, Kato H and Itoh K: Polymorphism of the 5'-flanking region of the human tumor necrosis factor (TNF)-alpha gene in Japanese. Tissue Antigens 51: 605-612, 1998.

10. Sterne JA, Egger M and Smith GD: Systematic reviews in health care: Investigating and dealing with publication and other biases in meta-analysis. BMJ 323: 101-105, 2001.

11. Jia A, Gong J, Li YC and Hao ZM: Correlation between polymorphisms of IL-4, tumor necrosis factor alpha gene and non-cardiac gastric cancer in Han people of Shaanxi province. Chin J Gastroenterol Hepatol 17: 642-644, 2008.

12. Canedo P, Durães C, Pereira F, Regalo G, Lunet N, Barros H, Carneiro F, Seruca R, Rocha J and Machado JC: Tumor necrosis factor alpha extended haplotypes and risk of gastric carcinoma. Cancer Epidemiol Biomarkers Prev 17: 2416-2420, 2008.
13. Crusius JB, Canzian F, Capellá G, Peña AS, Pera G, Sala N, Agudo A, Rico F, Del Giudice G, Palli D, et al: Cytokine gene polymorphisms and the risk of adenocarcinoma of the stomach in the European prospective investigation into cancer and nutrition (EPIC-EURGAST). Ann Oncol 19: 1894-1902, 2008.

14. Dong Y, Qisan W, Fei W and Tao M: Relationship between tagSNPs and haplotype of TNF-A gene and gastric cancer in Uygur and Han ethnic groups in Xinjiang. Carcinogenesis. Teratogenesis Mutagen 24: 261-265, 2012.

15. El-Omar EM, Rabkin CS, Gammon MD, Vaughan TL, Risch HA, Schoenberg JB, Stanford JL, Mayne ST, Goedert J, Blot WJ, et al: Increased risk of noncardia gastric cancer associated with proinflammatory cytokine gene polymorphisms. Gastroenterology 124: 1193-1201, 2003.

16. Fei BY, Xia B, Deng CS, Xia XQ, Xie M, Crusius JB and Pena AS: Association of tumor necrosis factor genetic polymorphism with chronic atrophic gastritis and gastric adenocarcinoma in Chinese Han population. World J Gastroenterol 10: 1256-1261, 2004.

17. García-González MA, Lanas A, Quintero E, Nicolás D, Parra-Blanco A, Strunk M, Benito R, Angel Simón M, Santolaria S, Sopeña F, et al; Spanish Gastroenterological Association AEG: Gastric cancer susceptibility is not linked to pro-and anti-inflammatory cytokine gene polymorphisms in whites: A Nationwide Multicenter Study in Spain. Am J Gastroenterol 102: 1878-1892, 2007.

18. Garza-González E, Bosques-Padilla FJ, El-Omar E, Hold G, Tijerina-Menchaca R, Maldonado-Garza HJ and Pérez-Pérez GI: Role of the polymorphic IL-1B, IL-1RN and TNF-A genes in distal gastric cancer in Mexico. Int J Cancer 114: 237-241, 2005.

19. Glas J, Török HP, Schneider A, Brünnler G, Kopp R, Albert ED, Stolte $\mathrm{M}$ and Folwaczny C: Allele 2 of the interleukin-1 receptor antagonist gene is associated with early gastric cancer. J Clin Oncol 22: 4746-4752, 2004

20. Guo W, Wang N, Li Y and Zhang JH: Polymorphisms in tumor necrosis factor genes and susceptibility to esophageal squamous cell carcinoma and gastric cardiac adenocarcinoma in a population of high incidence region of North China. Chin Med J (Engl) 118: 1870-1878, 2005.

21. Hong Y, Ge Z, Jing C, Shi J, Dong X, Zhou F, Wang M, Zhang Z and Gong W: Functional promoter $-308 \mathrm{G}>\mathrm{A}$ variant in tumor necrosis factor $\alpha$ gene is associated with risk and progression of gastric cancer in a Chinese population. PLoS One 8: e50856, 2013.

22. Hou L, El-Omar EM, Chen J, Grillo P, Rabkin CS, Baccarelli A, Yeager M, Chanock SJ, Zatonski W, Sobin LH, et al: Polymorphisms in Th1-type cell-mediated response genes and risk of gastric cancer. Carcinogenesis 28: 118-123, 2007.

23. Jang WH, Yang YI, Yea SS, Lee YJ, Chun JH, Kim HI, Kim MS and Paik KH: The -238 tumor necrosis factor-alpha promoter polymorphism is associated with decreased susceptibility to cancers. Cancer Lett 166: 41-46, 2001.

24. Kamangar F, Abnet CC, Hutchinson AA, Newschaffer CJ, Helzlsouer K, Shugart YY, Pietinen P, Dawsey SM, Albanes D, Virtamo J, et al: Polymorphisms in inflammation-related genes and risk of gastric cancer (Finland). Cancer Causes Control 17: $117-125,2006$

25. Kim N, Cho SI, Yim JY, Kim JM, Lee DH, Park JH, Kim JS, Jung HC and Song IS: The effects of genetic polymorphisms of IL-1 and TNF-A on Helicobacter pylori-induced gastroduodenal diseases in Korea. Helicobacter 11: 105-112, 2006.

26. Lee JY, Kim HY, Kim KH, Kim SM, Jang MK, Park JY, Lee JH, Kim JH and Yoo JY: Association of polymorphism of IL-10 and TNF-A genes with gastric cancer in Korea. Cancer Lett 225: 207-214, 2005.

27. Lee SG, Kim B, Yook JH, Oh ST, Lee I and Song K: TNF/LTA polymorphisms and risk for gastric cancer/duodenal ulcer in the Korean population. Cytokine 28: 75-82, 2004.

28. Li C, Xia B, Yang Y, Li J and Xia HH: TNF gene polymorphisms and Helicobacter Pylori infection in gastric carcinogenesis in Chinese population. Am J Gastroenterol 100: 290-294, 2005.

29. Lu W, Pan K, Zhang L, Lin D, Miao X and You W: Genetic polymorphisms of interleukin (IL)-1B, IL-1RN, IL-8, IL-10 and tumor necrosis factor alpha\} and risk of gastric cancer in a Chinese population. Carcinogenesis 26: 631-636, 2005.

30. Machado JC, Figueiredo C, Canedo P, Pharoah P, Carvalho R, Nabais S, Castro Alves C, Campos ML, Van Doorn LJ, Caldas C, et al: A proinflammatory genetic profile increases the risk for chronic atrophic gastritis and gastric carcinoma. Gastroenterology 125: 364-371, 2003. 
31. Melo Barbosa HP, Martins LC, Dos Santos SE, Demachki S, Assumpção MB, Aragão CD and de Oliveira Corvelo TC: Interleukin-1 and TNF- $\alpha$ polymorphisms and Helicobacter pylori in a Brazilian Amazon population. World J Gastroenterol 15: 1465-1471, 2009.

32. Morgan DR, Dominguez RL, Keku TO, Heidt PE, Martin CF Galanko JA, Omofoye OA and Sandler RS: Gastric cancer and the high combination prevalence of host cytokine genotypes and Helicobacter pylori in Honduras. Clin Gastroenterol Hepatol 4: 1103-1111, 2006.

33. Ohyama I, Ohmiya N, Niwa Y, Shirai K, Taguchi A, Itoh A, Hirooka Y, Wakai K, Hamajima N, Mori N, et al: The association between tumour necrosis factor-alpha gene polymorphism and the susceptibility to rugal hyperplastic gastritis and gastric carcinoma. Eur J Gastroenterol Hepatol 16: 693-700, 2004.

34. Oliveira JG, Duarte MC and Silva AE: IL-1 ra anti-inflammatory cytokine polymorphism is associated with risk of gastric cancer and chronic gastritis in a Brazilian population, but the TNF- $\beta$ pro-inflammatory cytokine is not. Mol Biol Rep 39: 7617-7625, 2012.

35. Perri F, Piepoli A, Bonvicini C, Gentile A, Quitadamo M, Di Candia M, Cotugno R, Cattaneo F, Zagari MR, Ricciardiello L, et al: Cytokine gene polymorphisms in gastric cancer patients from two Italian areas at high and low cancer prevalence. Cytokine 30: 293-302, 2005.

36. Santos JC, Ladeira MS, Pedrazzoli J Jr and Ribeiro ML: Relationship of IL-1 and TNF- $\alpha$ polymorphisms with Helicobacter pylori in gastric diseases in a Brazilian population. Braz J Med Biol Res 45: 811-817, 2012.

37. Sugimoto M, Furuta T, Shirai N, Nakamura A, Xiao F, Kajimura M, Sugimura H and Hishida A: Different effects of polymorphisms of tumor necrosis factor-alpha and interleukin-1 beta on development of peptic ulcer and gastric cancer. J Gastroenterol Hepatol 22: 51-59, 2007.

38. Wu MS, Chen LT, Shun CT, Huang SP, Chiu HM, Wang HP Lin MT, Cheng AL and Lin JT: Promoter polymorphisms of tumor necrosis factor-alpha are associated with risk of gastric mucosa-associated lymphoid tissue lymphoma. Int J Cancer 110: 695-700, 2004

39. Wu MS, Huang SP, Chang YT, Shun CT, Chang MC, Lin MT Wang HP and Lin JT: Tumor necrosis factor-alpha and interleukin-10 promoter polymorphisms in Epstein-Barr virus-associated gastric carcinoma. J Infect Dis 185: 106-109, 2002.

40. Wu MS, Wu CY, Chen CJ, Lin MT, Shun CT and Lin JT: Interleukin-10 genotypes associate with the risk of gastric carcinoma in Taiwanese Chinese. Int J Cancer 104: 617-623, 2003.
41. Yang JJ, Ko KP, Cho LY, Shin A, Gwack J, Chang SH, Shin HR, Yoo KY, Kang D and Park SK: The role of TNF genetic variants and the interaction with cigarette smoking for gastric cancer risk: A nested case-control study. BMC Cancer 9: 238, 2009.

42. Yea SS, Yang YI, Jang WH, Lee YJ, Bae HS and Paik KH: Association between TNF- $\alpha$ promoter polymorphism and Helicobacter pylori cagA subtype infection. J Clin Pathol 54: 703-706, 2001.

43. Zambon CF, Basso D, Navaglia F, Belluco C, Falda A, Fogar P, Greco E, Gallo N, Rugge M, Di Mario F, et al: Proand anti-inflammatory cytokines gene polymorphisms and Helicobacter pylori infection: Interactions influence outcome. Cytokine 29: 141-152, 2005.

44. Zeng QD, Lü LH, Xing PX, Lü B and Wang YS: Relationship between cytokine gene polymorphism and development of gastric adenocarcinoma. Zhonghua Yi Xue Za Zhi 87: 1037-1039, 2007 (In Chinese).

45. Zhou P, Lv GQ, Wang JZ, Li CW, Du LF, Zhang C and Li JP: The TNF- $\alpha-238$ polymorphism and cancer risk: A meta-analysis. PLoS One 6: e22092, 2011.

46. Peleteiro B, Lunet N, Carrilho C, Durães C, Machado JC, La Vecchia C and Barros H: Association between cytokine gene polymorphisms and gastric precancerous lesions: Systematic review and meta-analysis. Cancer Epidemiol Biomarkers Prev 19: 762-776, 2010.

47. Persson C, Canedo P, Machado JC, El-Omar EM and Forman D: Polymorphisms in inflammatory response genes and their association with gastric cancer: A HuGE systematic review and meta-analyses. Am J Epidemiol 173: 259-270, 2011.

48. Wang J, Cao C, Luo H, Xiong S, Xu Y and Xiong W: Tumour necrosis factor alpha -308G/A polymorphism and risk of the four most frequent cancers: A meta-analysis. Int J Immunogenet 38: 311-320, 2011.

49. Lu PH, Tang Y, Li C, Shen W, Ji L, Guo YJ and Tao GQ: Meta-analysis of association of tumor necrosis factor alpha-308 gene promoter polymorphism with gastric cancer. Zhonghua $\mathrm{Yu}$ Fang Yi Xue Za Zhi 44: 209-214, 2010 (In Chinese).

50. Peek RM Jr and Blaser MJ: Helicobacter pylori and gastrointestinal tract adenocarcinomas. Nat Rev Cancer 2: 28-37, 2002.

51. Zang G, Miao L, Mu Y, Qiao C, Liu J, Ke X, Zheng C and Sun H Adenoviral mediated transduction of adenoid cystic carcinoma by human TRAIL gene driven with hTERT tumor specific promoter induces apoptosis. Cancer Biol Ther 8: 966-972, 2009.

52. Yin Y, Chen W, Tang C, Ding H, Jang J, Weng M, Cai Y and Zou G: NF- $\kappa$ B, JNK and p53 pathways are involved in tubeimoside-1-induced apoptosis in HepG2 cells with oxidative stress and $\mathrm{G}_{2} / \mathrm{M}$ cell cycle arrest. Food Chem Toxicol 49: 3046-3054, 2011. 